\title{
TINGKAT KECEMASAN PASIEN SEBELUM DAN SESUDAH PEMBEDAHAN DI RUMAH SAKIT SWASTA YOGYAKARTA
}

\author{
Theresia Titin Marlina ${ }^{1}$ \\ ${ }^{1}$ Stikes Panti Rapih, Jl. Tantular 401, Pringwulung, Condong Catur, Depok, Sleman, Yogyakarta, 55823, \\ email: th77titin@gmail.com
}

\begin{abstract}
Background: Surgery is a major stressor for most patients. Preoperative anxiety determines the success or failure of surgery and recovery, as well as postoperative anxiety. The role of the nurses are very important in assessing the patient's anxiety. The giving of information about surgery and post-surgery manajemen are needed the patients.

Objective: The aims of this study is to determine the level of patients anxiety before and after surgery Methodes:This research is non experimental with cross sectional design. The population is all patients undergoing surgery, with a sample of 80 patients by accidental sampling. The instrument is HARS (Halmington Anxiety Rating Scala). Data collection on April 2015. Beginning with inform concent and then giving quisioner to patients. The questionnaires were administered before surgery and after the patients had surgery. Univariate analysis and paired t test are the analysis used.

Results: Middle anxiety levels before surgery are $45 \%$ to $25 \%$ after surgery. Mild anxiety levels before surgery are $34 \%$ to $10 \%$ after surgery. While the respondents who did not anxiety before surgery are $10 \%$ to $61,25 \%$ after surgery.

Conclusion: There was a significant difference in the patients anxiety levels before and after surgery with $\mathrm{p}$ $=0,00$.
\end{abstract}

Keywords : Anxiety, surgery, role of the nurses

\section{PENDAHULUAN}

Kecemasan adalah keadaan khawatir atau tegang dalam diri individu yang terjadi ketika kebutuhan interpersonal akan keamanan dan/atau kebebasan dari perasaan tegang tidak terpenuhi. ${ }^{1}$ Salah satu faktor yang memengaruhi kecemasan adalah terjadinya ketidakmampuan fisiologis atau menurunnya kapasitas fungsional sehari-hari akibat tindakan pembedahan yang akan dijalani. $^{2}$ Ketika seseorang mengalami kecemasan maka akan merangsang sistem saraf otonom yaitu peningkatan kerja kelenjar adrenal untuk melepas adrenalin yang menyebabkan meningkatnya frekuensi jantung. Peningkatan kinerja jantung ini menyebabkan peningkatan tekanan darah yang dapat berdampak buruk terhadap tindakan operasi yaitu pendarahan. ${ }^{3}$ Selain itu, penelitian lain menemukan bahwa kecemasan yang berlebihan akan menyebabkan pasien secara emosional tidak siap menghadapi pembedahan dan menunda operasi karena mengalami tandatanda fisiologis seperti peningkatan nadi perifer dan peningkatan tekanan darah. ${ }^{4}$

Selain berpengaruh terhadap proses pelaksanaan operasi, kecemasan ini juga berpengaruh terhadap pasien setelah dilaksanakan operasi. Kecemasan pasien paska pembedahan akan memengaruhi persepsi nyeri. Hubungan antara nyeri dengan kecemasan bersifat kompleks. Kecemasan dapat menimbulkan persepsi nyeri, begitu juga sebaliknya. Nyeri dapat 
menyebabkan kecemasan. Stimulus nyeri ini dapat mengaktifkan sistem limbic sebagai pengendali emosi seseorang. Sistem limbic dapat memproses reaksi emosi terhadap nyeri yaitu meningkatkan atau menurunkan tingkat nyeri. $^{5}$

Sebuah penelitian yang bertujuan mengetahui tingkat kecemasan pasien pre operasi, didapatkan hasil bahwa dari 30 responden terdapat 17 (56,7\%) responden mengalami kecemasan ringan, 12 (40\%) responden mengalami tingkat kecemasan sedang pada waktu sebelum pembedahan. ${ }^{6}$ Hal ini menunjukkan bahwa tindakan pembedahan merupakan salah satu faktor yang memengaruhi kecemasan pasien. Di sinilah peran perawat sangat dibutuhkan pasien untuk memberikan edukasi yang jelas, memberikan pendampingan psikologis bersama keluarga agar pasien siap dan tenang menjalani pembedahan.

Berdasarkan pengalaman peneliti berinteraksi dengan beberapa pasien yang akan dilakukan tindakan pembedahan, mereka mengatakan takut, sering menanyakan tentang operasinya dan bahkan ada yang meminta untuk ditemani. Demikian pula dengan pasien setelah dilakukan tindakan pembedahan, beberapa pasien mengatakan takut kalau jahitan operasinya lepas, tidak berani melakukan pergerakan dan sering menanyakan kapan lukanya kering.

Dengan mengetahui kecemasan pasien sebelum pembedahan, perawat dapat memberikan penjelasan dan memberi gambaran tentang proses pembedahan, apa yang harus dilakukan pasien ketika merasakan nyeri, melibatkan keluarga untuk mendampingi pasien sehingga pasien tidak merasakan cemas lagi. Sedangkan dengan mengetahui kecemasan paska pembedahan dapat dijadikan dasar untuk melakukan tindakan keperawatan yang tepat, sehingga pasien tidak mengalami komplikasi.

Tujuan penelitian ini adalah untuk mengetahui perbedaan tingkat kecemasan sebelum dan sesudah pembedahan.

\section{BAHAN DAN CARA PENELITIAN}

Penelitian ini merupakan penelitian non eksperimental, dengan rancangan penelitian cross sectional untuk mengetahui perbedaan tingkat kecemasan pada pasien sebelum dan setelah dilakukan tindakan pembedahan. Penelitian ini dilakukan di salah satu rumah sakit swasta di Yogyakarta pada bulan April 2015, dengan jumlah sampel 80 orang. Uji normalitas dalam penelitian ini, didapatkan nilai Shapiro wilk $>0,05$ yaitu $p=0,84$ artinya bahwa data terdistribusi normal. Maka analisis data menggunakan uji t berpasangan. Instrumen yang digunakan menggunakan instrument baku kecemasan HARS (Halmington Anxiety Rating Scale). Validitas instrumen ini dengan nilai corrected item total correlation 0,46 $(>0.05)$ dan reliabilitasnya dengan nilai Cronbach's alpha 0.77 (>0.05). 
HASIL DAN PEMBAHASAN

\section{Karakteristik responden}

Tabel 1

Distribusi frekuensi responden berdasarkan Jenis Kelamin, Usia, Suku dan Pendidikan

Pasien Operasi Di Rumah Sakit Swasta Yogyakarta $\mathbf{N}=\mathbf{8 0}$

\begin{tabular}{|c|c|c|c|}
\hline No. & Karakteristik responden & & nden \\
\hline & & & $(\%)$ \\
\hline 1. & $\begin{array}{c}\text { Jenis Kelamin : } \\
\text { Laki-laki }\end{array}$ & 35 & 43.75 \\
\hline & Perempuan & 45 & 56,25 \\
\hline 2. & Usia : & & \\
\hline & $21-30$ & 32 & 40 \\
\hline & $31-40$ & 14 & 17,5 \\
\hline & $41-50$ & 12 & 15 \\
\hline & $51-60$ & 22 & 27,5 \\
\hline 3. & Suku : & & \\
\hline & Jawa & 75 & 93,75 \\
\hline & Bugis & 3 & 3,75 \\
\hline & Batak & 1 & 1,25 \\
\hline & Tionghoa & 1 & 1,25 \\
\hline 4. & Pendidikan : & & \\
\hline & SD & 1 & 1,25 \\
\hline & SLTP & 1 & 1,25 \\
\hline & SLTA & 37 & 46,25 \\
\hline & Perguruan Tinggi & 41 & 51,25 \\
\hline & Jumlah & 80 & 100 \\
\hline
\end{tabular}

Sumber: Data primer, 2015

Berdasarkan Tabel 1. Jumlah responden perempuan lebih banyak dibandingkan laki-laki yaitu 56,25\%, kurang dari separuh (40\%) berusia 21-30 tahun, sebagian besar $(93,75 \%)$ bersuku Jawa dan kurang dari separuh (41\%) berpendidikan perguruan tinggi.

Banyak faktor yang memengaruhi kecemasan sebelum pembedahan. Berdasarkan hasil sebuah penelitian bahwa faktor yang memengaruhi kecemasan pasien sebelum operasi $46,7 \%$ adalah faktor umur dan pekerjaan. $^{7}$ Pada penelitian ini persentase terbesar responden berusia 21-30 tahun atau berada pada tahap dewasa muda. Usia berpengaruh terhadap kematangan berpikir seseorang yang tercermin dalam menyikapi permasalahan yang dihadapi. Usia dewasa muda biasanya seseorang ingin menunjukkan potensi dirinya atau aktualisasi diri, sehingga ketika mengalami ancaman fisik seperti pembedahan maka respon cemas akan meningkat.

Hasil penelitian ini, lebih dari separuh $(56,25 \%)$ responden berjenis kelamin perempuan. Respon cemas seorang perempuan lebih tinggi dibandingkan lakilaki. Hal ini disebabkan perempuan lebih peka dan sangat menonjolkan perasaannya daripada logikanya. Dengan stimulus yang sama, respon cemas perempuan lebih tinggi dibandingkan laki-laki. Emosional laki-laki lebih stabil, dan laki-laki lebih enggan menunjukkan ketakutan mereka kepada orang lain. $^{2}$ Perempuan memiliki tingkat toleransi yang rendah terhadap rasa sakit sehingga melaporkan tingkat kecemasan yang lebih tinggi.

Setelah pembedahan, terjadi peningkatan jumlah responden yang tidak cemas sebesar 51,25\%. Hal ini dimungkinkan karena pasien masih dalam pengaruh anestesi sehingga belum sepenuhnya merasakan nyeri.

\section{Perbedaan Kecemasan Pasien Sebelum dan Setelah Operasi}

Uji beda dilakukan untuk mengetahui perbedaan tingkat kecemasan sebelum dan 
sesudah dilakukan tindakan pembedahan. Sebelumnya dilakukan uji normalitas dengan nilai Shapiro wilk $>0,05$ yaitu $p=0,84$ artinya bahwa data terdistribusi normal. Maka uji yang digunakan adalah uji t berpasangan.

Tabel 2.

Distribusi Kategori Tingkat Kecemasan

Sebelum Dan Sesudah Pembedahan

Pada Pasien Di Rumah Sakit Swasta Yogyakarta $\mathbf{N}=\mathbf{8 0}$

\begin{tabular}{lcc}
\hline $\begin{array}{c}\text { Tingkat } \\
\text { Kecemasan }\end{array}$ & $\begin{array}{c}\text { Sebelum } \\
\text { operasi }\end{array}$ & $\begin{array}{c}\text { Setelah } \\
\text { operasi }\end{array}$ \\
\cline { 2 - 3 } & $\begin{array}{c}\text { Jumlah dan } \\
\text { persentase }\end{array}$ & $\begin{array}{c}\text { Jumlah dan } \\
\text { persentase }\end{array}$ \\
\hline Tidak cemas & $8(10 \%)$ & $49(61,25 \%)$ \\
Cemas ringan & $34(42,5 \%)$ & $8(10 \%)$ \\
Cemas sedang & $36(45 \%)$ & $20(25 \%)$ \\
Cemas berat & $2(2,5 \%)$ & $3(3,75 \%)$ \\
Jumlah & $80(100 \%)$ & $80(100 \%)$ \\
\hline
\end{tabular}

Sumber: Data primer, 2015

Berdasarkan tabel 2, dapat dilihat bahwa terjadi penurunan persentase tingkat cemas sedang sebelum pembedahan $45 \%$ menjadi $25 \%$ setelah pembedahan, cemas ringan sebelum pembedahan $42,5 \%$ menjadi $10 \%$ setelah pembedahan. Sedangkan responden yang tidak mengalami kecemasan sebelum pembedahan sebesar $10 \%$ meningkat menjadi $61,25 \%$ setelah pembedahan.

Tingkat kecemasan responden sebelum pembedahan lebih banyak berada pada tingkat sedang dibandingkan ringan. Hal ini dimungkinkan karena kematangan pribadi, pemahaman tentang proses pembedahan, harga diri, dan mekanisme koping. ${ }^{8} \quad$ Seseorang yang memiliki kematangan pribadi yang baik, mampu menerima informasi perawat mengenai proses pembedahan dengan baik.
Kematangan pribadi dan mekanisme koping ini akan menjadi baik seiring dengan bertambahnya usia. Pada penelitian ini, sebagian responden pada usia dewasa, sehingga dapat diasumsikan bahwa responden memiliki kematangan emosi dan mekanisme koping yang baik.

Berdasarkan hasil penelitian ini, terdapat perbedaan signifikan $(p<0,05)$ antara tingkat kecemasan sebelum dan sesudah pembedahan. Kecemasan sebelum pembedahan sering dihubungkan dengan pengetahuan dan pemahaman yang salah serta kurangnya informasi yang tepat mengenai proses pembedahan sebelum, selama, dan sesudah prosedur. ${ }^{9}$ Penelitian lain juga menyebutkan bahwa terdapat hubungan signifikan antara tingkat pengetahuan dengan tingkat kecemasan dengan $p=0,00 .{ }^{10}$ Semakin tinggi pengetahuan seseorang maka akan lebih mudah menerima dan memahami informasi yang diberikan sehingga kecemasannya berkurang. ${ }^{11}$

Pendapat lain mengenai faktor yang dapat menyebabkan kecemasan pasien sebelum pembedahan adalah disebabkan karena takut terhadap nyeri, takut mati, takut mengalami deformitas, dan ancaman lain terhadap citra tubuh, masalah finansial, tanggung jawab terhadap keluarga, ketakutan terhadap prognosis yang buruk, dan ancaman ketidakmampuan permanen akibat pembedahan. ${ }^{11}$ Hasil penelitian lain membuktikan bahwa faktor internal yang 
paling besar menyebabkan kecemasan adalah usia dan pekerjaan (46,7\%), sedangkan faktor eksternal yang paling besar adalah dukungan keluarga $(60 \%){ }^{7}$

Kecemasan setelah operasi menunjukkan data bahwa $3,75 \%$ cemas berat, $10 \%$ cemas ringan, $25 \%$ cemas sedang, dan 61,25\% tidak cemas. Meskipun persentase cemas setelah pembedahan tidak besar, namun kecemasan setelah pembedahan harus mendapat perhatian serius oleh tim kesehatan. Karena kecemasan ini akan memengaruhi proses kesembuhan pasien. Kondisi cemas akan meningkatkan pelepasan renin, angiotensin, aldosteron, dan kortisol yang menyebabkan vasokonstriksi pembuluh darah sehingga suplai darah ke jantung menurun. Selain itu dengan adanya kecemasan juga merangsang hipotalamus untuk memproduksi corticotrophin releasing factor (CRF) yang berfungsi merangsang kelenjar pituitary anterior meningkatkan produksi adeno cortiko tropin hormone (ACTH). Hormon ini akan meningkatkan sekresi kortisol dari korteks adrenal. Semakin banyak kortisol yang dihasilkan akan menyupresi sistem imun seseorang. ${ }^{5}$

Kecemasan setelah pembedahan juga sering disebabkan karena rasa nyeri. Sebuah penelitian membuktikan adanya hubungan yang signifikan antara nyeri dan kecemasan paska operasi dengan $p=0,015 .^{12}$ Penelitian serupa juga membuktikan bahwa terdapat hubungan signifikan antara tingkat nyeri dengan kecemasan pasien paska operasi dengan $\mathrm{p}=0,028 .{ }^{13}$ Nyeri merupakan hal yang lazim terjadi setelah pembedahan, namun skala nyeri sangat bervariasi tergantung bagaimana orang itu mempersepsikan nyeri, pengalaman nyeri sebelumnya, ataupun kematangan psikologisnya. ${ }^{7}$

Tabel 3.

Perbedaan tingkat kecemasan

Sebelum Dan Sesudah Pembedahan

Pada Pasien di Rumah Sakit Swasta Yogyakarta

\begin{tabular}{ccccc}
\hline $\begin{array}{c}\text { Skor } \\
\text { pre \& }\end{array}$ & Mean & $\begin{array}{c}\text { St } \\
\text { deviasi }\end{array}$ & $\begin{array}{c}\text { P } \\
\text { value }\end{array}$ & $\mathbf{N}$ \\
\cline { 2 - 5 } post & 4.46250 & 5.71018 & 0,00 & 80 \\
bedah & & & & \\
& & & & \\
& & & &
\end{tabular}

Sumber : data primer, 2015

Berdasarkan tabel 3, didapatkan hasil t test, dengan $p=0,00$ yang artinya bahwa terdapat perbedaan signifikan tingkat kecemasan sebelum dengan setelah menjalani pembedahan.

Sumber kecemasan sebelum pembedahan adalah pembedahan itu sendiri, sedangkan setelah pembedahan adalah rasa nyeri. Berdasarkan uji hipotesis didapatkan data bahwa terjadi perbedaan signifikan cemas sebelum dengan sesudah pembedahan. Hal ini dimungkinkan karena sumber cemas adalah pembedahan itu sendiri. Setelah pembedahan selesai, maka cemas pasien turun.

Berdasarkan hasil penelitian ini, sangat jelas peran perawat dalam menyiapkan 
psikologis pasien dengan memberikan pendidikan kesehatan tentang tindakan pembedahan, mendampingi pasien, bersikap empati, dan memberikan kesempatan kepada pasien untuk mengungkapkan perasaannya dan kecemasannya. Dengan kita menggali perasaan pasien, kita dapat mengidentifikasi sumber cemasnya dan menentukan tindakan efektif untuk mengurangi cemas. Jika cemas tinggi, kita dapat melakukan kolaborasi pengobatan dengan dokter. Karena jika cemas tinggi sebelum pembedahan tidak tertangani, maka akan berisiko terhadap proses pembedahan dan perawatan pasien setelah pembedahan. Pasien bisa mengalami pendarahan, karena dampak dilepaskannya adrenalin yang menyebabkan meningkatnya frekuensi jantung, dan peningkatan tekanan darah. ${ }^{14}$

\section{KESIMPULAN}

Persentase cemas responden sebelum pembedahan adalah $45 \%$ cemas sedang, dan $42,5 \%$ cemas ringan, sedangkan setelah pembedahan $61,25 \%$ tidak cemas dan $25 \%$ cemas sedang. Hasil penelitian ini secara statistik terdapat perbedaan signifikan tingkat kecemasan sebelum dengan sesudah dilakukan pembedahan.

Perawat dapat memberikan gambaran tentang tindakan yang akan dilakukan, tindakan yang pasien harus lakukan ketika nyeri paska pembedahan, memberikan pendampingan dan melibatkan keluarga untuk memberi dukungan kepada pasien.

\section{TERIMA KASIH}

Terima kasih kepada Andi Kristiawan selaku pengumpul data penelitian.

\section{KEPUSTAKAAN}

1. Murwani, A. Pengantar Konsep Dasar Keperawatan. Cetakan Pertama. Yogyakarta: Penerbit Fitramaya. 2008

2. Jaya, K. Keperawatan Jiwa. Tangerang : Binarupa Aksara Publisher. 2015

3. Videbeck, Sheila L,. Buku Ajar Keperawatan Jiwa. Jakarta: EGC. 2008

4. Meredekawati, D, Sagiran, Khoiriyati, A. Efektivitas Terapi Psikoedukasi dan Terapi Murattal Terhadap Kecemasan Pasien Preoperasi Fraktur di Ruang Perawatan Bedah Rsud Raden Mattaher Jambi. 2013. Diakses dari http://thesis.umy.ac.id/ datapublik/t33392.docx pada tanggal 20 Oktober 2017

5. Potter \& Perry. Fundamentals of Nursing $8^{\text {th }}$ Edition. Elsevier Mosby. 2013

6. Uskenat, MD, Kristiyawati, SP, Solechan, A. Perbedaan tingkat kecemasan pada pasien pre operasi dengan general anestesi sebelum dan sesudah diberikan relaksasi otot progresif di RS Panti Wilasa Citarum Semarang. 2012. Diakses dari http://ejournal.stikestelogorejo.ac.id/inde x.php/ilmukeperawatan/article/view/64 pada tanggal 20 Oktober 2017

7. Ahsan, Lestari R, Sriati. Faktor-faktor yang memengaruhi kecemasan pre operasi pada pasien section caesaria di ruang Bedah Sentral RSUD kanjuruhan Kepanjen kabupaten Malang. Jurnal Muhammadiyah Malang Volume 8, No.1 Januari 2017. Diakses dari http://ejournal.umm.ac. id/index.php/keperawatan/issue/view pada tanggal 19 Oktober 2017.

8. Stuart, Gail W. Buku Saku Keperawatan Jiwa. Jakarta : EGC. 2007 
9. Setyaningsih, et al. Perbedaan tingkat kecemasan pre dan post operasi di Bangsal Bedah Kenanga RSUD Prof Dr Margono Soekarjo periode 1-5 Oktober 2012. Mandala of Health, volume 6, No. 1, Januari 2013. Diakses dari http://www.portalgaruda. org/article.php? pada tanggal 20 Oktober 2017

10. Santosa, B. Hubungan antara karakteristik demograsfi dengan kecemasan pasien pra operasi di RS Isalam Amal Sehat Sragen tahun 2008. Diakses dari http://www.skripsistikes.wordpress.com pada tanggal 21 Oktober 2017

11. Muttaqin A, Sari, K. Asuhan Keperawatan Perioperatif: Konsep, Proses dan Aplikasi. Jakarta: Salemba Medika. 2009

12. Sagala, AP. Hubungan nyeri dengan tingkat kecemasan pada pasien kanker yang menjalani kemoterapi di RS Dr Zainoel Abidin banda Aceh. 2014.
Diakses dari

http://www.etd.unsyiah.ac.id/baca/notfou nd.php pada tanggal 19 Oktober 2017

13. Iskak M, Manan S, Hotmaida L. (2015). Hubungan antara tingkat nyeri dengan tingkat kecemasan pasien post operasi di Ruang Filipus dan Elisabeth RS Immanuel bandung. Immanuel Jurnal IImu Kesehatan Volume 9, No.1, Juni 2015. Diakses dari http://ejournal.stikimmanuel.ac.

id/file. php?file $=$ jurnal\&id $=515 \& \mathrm{~cd}=$ e8916294d13c611dd07d432170daf1a9 \&name $=469 \% 20-\% 20478 \% 20$ Srihesty \%20 Manan.pdf pada tanggal 20 Oktober 2017

14. Smeltzer,SC, Bare Brenda G, Hinkle Janice L, Cheever Kerry H. Brunner \& Suddarth Textbook of Medical-Surgical Nursing Eleventh Edition. Volume 2. Lippincott Williams \& Wilkins. Philadelphia. 2013. 